less. The control group of five was small and there were no changes in blood pressure over the follow up period. After six months' relaxation treatment plasma $\mathrm{DBH}$ activity was significantly lower in the "treated" group (but only in the upright position, whereas blood pressure was lower both supine and upright) and not different in controls. Neither group, however, showed significant differences in plasma renin activity after six months' treatment.

These studies show the need for carefully designed controlled trials in the evaluation of any form of treatment in hypertension. They also emphasise the importance of alteration of central nervous system activity in both the pathogenesis and treatment of hypertension. In animals stimulation of the hypothalamus results in haemodynamic changes similar to those found in early labile hypertension-namely, increased cardiac output, tachycardia, and peripheral vasoconstriction. ${ }^{11}$ These changes may persist after removal of hypothalamic stimulation; and, moreover, experimental hypertension induced by renal surgery or by salt overload may be shown to be sustained by central mechanisms, while prior destruction of central catecholaminergic pathways prevents any rise in blood pressure. ${ }^{1213}$ Alteration of central sympathetic activity by drugs such as methyldopa, clonidine, or propranolol can prevent the long-term ravages of raised blood pressure. Finally, these studies raise the possibility that control of blood pressure in some well-motivated patients with mild hypertension may be possible without drugs. The scope of these techniques remains to be defined; the feasibility of their widespread application is uncertain; and there is no immediate suggestion that physicians' efforts to lower blood pressure with drugs will be replaced wholesale by relaxation techniques. But, in a few years, who knows?

\footnotetext{
${ }^{1}$ Hawthorne, V M, Greaves, D A, and Beevers, D G, British Medical Fournal, 1974, 3, 600 .

2 Pickering, G W, Hypertension, 2nd edn. Edinburgh, Churchill Livingstone, 1974 .

3 Veterans Administration Cooperative Study Group, Fournal of the American Medical Association, 1970, 213, 1143.

Peart, W S, and Miall, W E, Lancet, 1975, 2, 1093.

5 Patel, C, and North, W R S, Lancet, 1975, 2, 93.

6 Patel, C, Lancet, 1975, 1, 62.

${ }^{7}$ Blackwell, B, et al, Lancet, 1976, 1, 223.

${ }^{8}$ Stone, R, and De Leo, J, New England Fournal of Medicine, 1976, 294, 80.

${ }^{9}$ DePotter, W P, et al, fournal of Physiology, 1969, 204, 102p.

10 Vander, A J, American fournal of Physiology, 1964, 209, 652.

11 Folkow, B, and Rubinstein, E H, Acta Physiologica Scandinavica, 1966, 68, 48.

12 Chalmers, J P, et al, fournal of Physiology, 1974, 238, 402.

${ }^{13}$ Haeusler, G, Finch, L, and Thoenen, H, Experientia, 1972, 28, 1200.
}

\section{Management of motor neurone disease}

The enigma of motor neurone disease in its usual adult sporadic form has remained virtually untouched by the advances in medicine of the past century. Theories of causation either cannot be confirmed ${ }^{1}$ or do not seem to be of general application. ${ }^{2}$ No convincing or consistent link with systemic disease has been established, and the pathological features remain obstinately those of neuronal degeneration. The total absence of curative treatment and the almost invariably progressive course throw a heavy emphasis on the practical and humane management of the patient and of his symptoms.
Motor neurone disease is fortunately not common, though the neurologist may obtain an erroneous impression to the contrary, as second or third opinions are naturally often sought. In most studies the prevalence has been around 4 per 100000 population, the annual death rate about 1 per 100000 , and the average duration of the disease about three years. ${ }^{3}$ But in $10 \%$ of patients with otherwise apparently identical disease, sometimes even including bulbar palsy, survival is much longer, up to ten years or more. ${ }^{4}$ It is predominantly a disease of the second half of life, $98 \%$ of deaths occurring ${ }^{5}$ after the age of 40 . It has been claimed, though unconvincingly, that survival is longer when the onset is after the age of 65.6 Men are affected more than women in a ratio of 1.6 to 1 . In most cases no genetic influence can be detected, and there is no evidence that motor neurone disease is becoming more common."

The early case may present diagnostic difficulty, but all too easily alternatives are excluded and spreading wasting weakness and fasciculation declare the fatal nature of the disease. When the diagnosis is established beyond doubt the physician must decide what to tell the patient. Most will rightly flinch from an immediate bald statement of inexorable creeping paralysis leading to death from choking or suffocation, but with the passage of time the patient must surely be told, rather than be allowed to guess, that the disease is incurable. In contrast to cancer or leukaemia, for which in any case there is treatment, patients are not intellectually or emotionally prepared for a paralysing disease of which they have never heard and which nobody seems to understand. Both the inevitability of deterioration and death and the details of the often protracted terminal stages are indeed such that it is difficult to reply frankly to the questions of the patient or even of the relatives. The distress, and in particular the panic induced by respiratory weakness, were soberly but movingly described by Henke,? herself a victim.

Little guidance on the management of the advanced disease can be obtained from standard texts. Treatment must be directed to relieving suffering and only rarely to prolonging life. In his account of 22 patients cared for in hospital for several months before death, Rosin ${ }^{8}$ described overt mental anguish in 15. He urged sustained personal involvement of the staff with the often speechless patient, involvement that can be exacting and even harrowing. Many of us tend to turn with embarrassment from patients whom we cannot help, and even to behave as if the patient who cannot communicate is unable to understand. Vigorous physiotherapy is obviously out of place and only charts, all too plainly, declining strength, but passive movement is comforting to paralysed and sometimes painful limbs.

Dysphagia may be prominent before the disease has become generalised, and most patients eventually develop bulbar palsy. The malnutrition that may result is comparatively unimportant in the context but is sometimes given as a reason for active measures, whereas the distress of choking over interminable and unsatisfying meals should be the real indication. A nasogastric tube may be the solution, but some patients find this difficult to tolerate, and, if it is frequently changed, repeated swallowing of the tube can be almost as unpleasant as trying to swallow food. Gastrostomy is seldom employed but should certainly be considered if strength is otherwise well preserved. The operation of cricopharyngeal sphincterotomy appears promising-the rationale being that if the pharyngeal muscles are paralysed and do not contract they do not produce the stimulus for relaxation of the sphincter, which remains closed. This procedure has given good or moderate relief of dysphagia in a high proportion of cases. ${ }^{9}$ 
These feeding techniques do not prevent the inhalation of secretions; and when respiratory weakness does not allow adequate coughing fluid can be excluded only by the cuff of a tracheostomy tube or by surgical closure of the glottis. ${ }^{10}$ Respiratory weakness is invariable in the terminal stages, and once a tracheostomy tube has been introduced the time will inevitably come when assisted respiration needs to be considered for the patient's respiratory distress. A decision to withhold treatment at this stage can clearly be influenced by factors other than the interests of the patient, notably the natural emotions of the family and the morale of the nursing staff. With modern methods and an experienced team a patient with motor neurone disease can be kept alive for a prolonged period, alert and with intellect and insight usually intact, but helpless and without hope of recovery. Rosin ${ }^{8}$ concluded that on humanitarian grounds the respirator should not be used, and few would disagree. Death is sometimes sudden and unexplained, but usually results from pneumonia or respiratory failure. Distress, as well as pain, responds to opiates.

Far more attention should be paid to relieving depression, isolation, and fear, and some alleviation of dysphagia can be achieved, preferably without tracheostomy. Nevertheless, the full resources of intensive care are inappropriate.

\footnotetext{
${ }^{1}$ Brody, J A, et al, Science, 1965, 147, 1114.

2 Yase, Y, Lancet, 1972, 2, 292.

${ }^{3}$ Bobowick, A R, and Brody, J A, New England fournal of Medicine, 1973 288, 1047.

4 Vejiajiva, A, Foster, J B, and Miller, H, Fournal of the Neurological Sciences, 1967, 4, 299.

5 Bale, G S, Fournal of Chronic Diseases, 1975, 28, 305.

${ }^{6}$ Hodgkinson, H M, Age and Ageing, 1972, 1, 182.

7 Henke, E, British Medical fournal, 1968, 4, 765.

${ }^{8}$ Rosin, A J, Age and Ageing, 1976, 5, 37.

9 Smith, A C, et al, Lancet, 1965, 2, 1094.

${ }^{10}$ Mills, C P, Lancet, 1973, 1, 455.
}

\section{Pills for pimples}

Ten heads are better than one: so runs the idea behind any committee. Some who work in the NHS have learned to doubt the universal truth of this belief, but it is still a mark of respect for any clinical problem to have a national committee set up to examine it. Everyone who treats acne vulgaris with systemic antibiotics, and this must include many general practitioners, should be grateful for the careful report ${ }^{1}$ on the topic by an ad hoc committee on the use of antibiotics in dermatology (part of the American Academy of Dermatology).

In many patients acne can be controlled adequately by topical measures and may not need antibiotics, but the problem is still huge. In the United States, for example, $10 \%$ of all the tetracycline produced for human use is prescribed by dermatologists for acne. Yet many of the clinical trials on which this use is based can be faulted easily enough on technical grounds. The committee discarded all investigations which were not adequately controlled and found itself left with only 12 studies; these contained 14 drug treatment trials comparing one or other tetracycline with a placebo. Of these, six trials showed the tetracycline to be significantly better than the placebo at the $5 \%$ level; a further six trials showed no significant difference; and the final two trials were not presented in a form suitable for analysis. Despite this apparently even balance, the committee was in no doubt that tetracyclines are effective in acne, believing that the lack of statistical significance in five of the trials was due to factors such as small sample size and short duration of treatment.

Could the widespread use of tetracyclines, based on rather scanty data, be harming patients? The committee also considered reports on this question, but found no reports of definite abnormalities in kidney or liver function in a study of prolonged treatment with oxytetracycline in 170 patients. $^{2}$ Patients with acne tend to be young and in good health and may consequently suffer fewer side effects than debilitated patients given the same doses. The presence of renal disease should swing the choice of antibiotic towards one mainly metabolised by the liver, such as chlortetracycline, doxycycline, or erythromycin, rather than oxytetracycline and tetracycline. Allergic reactions to tetracyclines are rare, and phototoxicity is seen chiefly with demeclocycline. Massive infections with resistant organisms have not been a problem, and the main microbiological effects have been an increased incidence of vaginal candidosis and Gram-negative folliculitis of the face. The American committee's final verdict on tetracycline treatment in acne was that it is "rational, effective, and relatively safe."

Some patients with bad acne are not helped by systemic tetracyclines. The committee found evidence that erythromycin, clomocycline, and the trimethoprim-sulphamethoxazole combination are roughly as effective as tetracycline. Erythromycin is relatively non-toxic; hepatic dysfunction is seen mainly with erythromycin estolate, but not with the ethyl succinate or stearate, which may offer reasonable and effective alternatives to the tetracyclines. Clindamycin is also effective, but there have been reports of patients developing pseudomembranous colitis. ${ }^{3}$ In two recent studies of long-term clindamycin in acne, ${ }^{45}$ enough patients (nine of the 130) developed diarrhoea to make the drug unsuitable for routine use.

Perhaps the future management of severe acne will depend on first checking the antibiotic sensitivity of the patient's own strain of Corynebacterium acnes before choosing the right antibiotic. This may then be used topically in a vehicle designed to enhance penetration. Preliminary studies of this approach, using clindamycin in a vehicle containing $\mathrm{N}$-methyl-2pyrrolidone, have shown some promise ${ }^{6}$ - but no doubt this technique will create problems of its own for another committee to pounce on.

${ }^{1}$ Ad Hoc Committee on the Use of Antibiotics in Dermatology, Archives of Dermatology, 1975, 111, 1630.

2 Delaney, T J, Leppard, B J, and MacDonald, D M, Acta DermatoVenereologica, 1974, 54, 487.

${ }^{3}$ Wolfe, M S, Fournal of the American Medical Association, 1974, 229, 266. 4 Dantzig, P I, Archives of Dermatology, 1976, 112, 53.

5 Tan, S G, and Cunliffe, W J, British fournal of Dermatology, 1976, 94, 313.

${ }^{6}$ Resh, W, and Stoughton, R B, Archives of Dermatology, 1976, 112, 182.

\section{Migrants and cardiovascular disease}

International comparisons of cardiovascular death rates show considerable differences among countries. Though the different age structures of populations can be taken into account fairly easily, such studies are often hampered by diagnostic differences and varying practices of death certification. Surveys can be done of different populations with a uniform clinical procedure, and these have proved that differences in vital statistics 